\title{
The role of literary fiction in facilitating social science research
}

\author{
Bryan Yazell ${ }^{1,2 \bowtie}$, Klaus Petersen ${ }^{2,3}$, Paul Marx ${ }^{3,4,5}$ \& Patrick Fessenbecker ${ }^{6,7}$
}

Scholars in literature departments and the social sciences share a broadly similar interest in understanding human development, societal norms, and political institutions. However, although literature scholars are likely to reference sources or concepts from the social sciences in their published work, the line of influence is much less likely to appear the other way around. This unequal engagement provides the occasion for this paper, which seeks to clarify the ways social scientists might draw influence from literary fiction in the development of their own work as academics: selecting research topics, teaching, and drawing inspiration for projects. A qualitative survey sent to 13,784 social science researchers at 25 different universities asked participants to describe the influence, if any, reading works of literary fiction plays in their academic work or development. The 875 responses to this survey provide numerous insights into the nature of interdisciplinary engagement between these disciplines. First, the survey reveals a skepticism among early-career researchers regarding literature's social insights compared to their more senior colleagues. Second, a significant number of respondents recognized literary fiction as playing some part in shaping their research interests and expanding their comprehension of subjects relevant to their academic scholarship. Finally, the survey generated a list of literary fiction authors and texts that respondents acknowledged as especially useful for understanding topics relevant to the study of the social sciences. Taken together, the results of the survey provide a fuller account of how researchers engage with literary fiction than can be found in the pages of academic journals, where strict disciplinary conventions might discourage out-of-the-field engagement.

\footnotetext{
${ }^{1}$ Department for the Study of Culture, University of Southern Denmark, Odense M, Denmark. ${ }^{2}$ Danish Institute for Advanced Study, Odense M, Denmark.

${ }^{3}$ Danish Centre for Welfare Studies, University of Southern Denmark, Odense M, Denmark. ${ }^{4}$ Institute for Socio-Economics, Universität Duisburg-Essen, Essen, Germany. ${ }^{5}$ Institute of Labor Economics (IZA), Bonn, Germany. ${ }^{6}$ Program for Cultures, Civilizations, and Ideas, Bilkent University, Ankara, Turkey.

${ }^{7}$ Engineering Communication Program, University of Wisconsin-Madison, Madison, WI, USA. ${ }^{凶}$ email: yazell@sdu.dk
} 


\section{Introduction}

nterdisciplinary research has become the buzzword of university managers and funding agencies. It is said that researchers need to think out of the box, be innovative and agile, and-last but not least-be curious about other disciplines in order to solve the complex challenges of the modern world. The tension inevitably generated by calls for more interdisciplinary work between university administrators on the one side and researchers on the other risks obscuring a fundamental question: what exactly is new about interdisciplinary research in the first place? For all the handwringing about interdisciplinarity, there is no clear consensus about what the boundaries of a given discipline are in the first place. Debates have waged over the last several decades about the divisions between the sciences and the humanities, their origins, and possible methods for rectifying them. Perhaps most famously, British scientist and novelist C.P. Snow identified "two cultures" in the academy separated by "a gulf of mutual incomprehension" (1961, p. 4). According to Snow, "literary intellectuals" and "physical scientists" not only distrusted each other's pronouncements, but fundamentally saw the world differently (1961, p.4, 6). Although this assessment has been influential in framing these respective disciplines for decades, its presentation of a binary division between the hard sciences and the arts does not account for the fields of study with overlapping interests and, at times, borrowed methodological tools: the social sciences and literature departments.

The social sciences and literary studies share an indelible link by virtue of their twinned emergence as academic disciplines in the early twentieth century. Both disciplines in the broadest sense share a keen interest in understanding and describing human behavior and social relationships. However despite-or perhaps owing to-these similarities, the disciplines have historically identified themselves in terms of opposition. On one side, Émile Durkheim's Rules of Sociological Method, published in 1895, defined the discipline in terms of positivism and quantitative study. On the other side, foundational literature scholars such as Matthew Arnold and F.R. Leavis understood literary study as a crucial component to the project of invigorating the national culture: to identify among the mass of popular culture the most elite examples of art. Critics in this early school of literary study therefore understood literature less as a mirror of society and more as a way to access what is best about cultural ideals or humanistic achievement (Arnold, 1873; Leavis, 2011). In this early context, social scientists were more interested in making society itself the object of study. While the features of each respective field have undoubtedly changed dramatically over the past century, this underlying division regarding the "science" in the social science persists. If the social scientist and literature scholar can speak with some degree of shared comprehension, they nonetheless are beset by disciplinary boundaries that make the task of mutual exchange harder than it might otherwise appear.

The decision to better document the uses of literature within the social sciences was born from an overarching drive to understand literature's impact on researchers that often escape notice. After all, literary scholars are in general familiar with (if not thoroughly informed by) the works of sociologists, economists, and political scientists. Moreover, they are likely to be comfortable both with using the toolset of the social sciences in their own work and, more to the point, citing sociologists such as Émile Durkheim, Erving Goffman, and Bruno Latour. Over the last decade, for instance, several prominent literary scholars have advocated for a descriptive model for analyzing literary texts modeled on the social sciences (e.g., Love 2010; Marcus and Love, 2016). This relatively recent turn to the social sciences does not begin to consider, of course, the much longer history of literary scholars drawing critical concepts from the Frankfurt School (such as Theodor Adorno or Jürgen Habermas) or, more significantly, the works of Karl Marx. All of which is to say, one can easily expect references to sources broadly associated with the social sciences when reading a literary studies monograph.

However, if it is clear that literary scholars are familiar with prominent works by social scientists, it is much less apparent if the reverse is true. In an essay in World Politics, the political scientist Cathie Jo Martin outlines the profound insight literary sources can offer the field. Novels and other literary fiction provide "a site for imagining policy", help define shared group interests, and create narratives that legitimize systems of governance (Martin, 2019, p. 432). Elsewhere, Nobel prize-winning economist Robert J. Shiller calls for greater engagement with literature and fiction in Narrative Economics (2019). However, as we show below, cases of social scientists explicitly acknowledging literary sources are few and far in between. Rather than articulate yet another call for better dialog between the disciplines, we instead seek greater insight into the way social scientists are already referring to, engaging with, or simply using literature in their field as researchers and teachers. As explained in detail below, this task is not as straightforward as it may seem.

\section{Methods}

Our project proceeded in two steps. The first was a qualitative study of social science articles that included references to literary authors drawn from the collection of social science journals cataloged on the JSTOR digital library. The evaluation of literary references captured in our study (outlined below) made it possible to track the proliferation of literary sources across social science research and to create a loose typology of these uses. For the second step, we developed a survey for social science researchers to elaborate on how, if at all, their work engages with works of literary fiction. Before going into the field, the survey was tested and discussed with a small number of academics to ensure that the items capture the concepts of interest. The survey was then sent electronically to 13,784 researchers at all stages (from $\mathrm{PhD}$ students to full professors) from the top 25 social science departments as ranked in 2019 by Times Higher Education (World University Rankings).

If academic departments are guardians of their disciplines, then this sample of prominent departments might reflect the international standard for their respective fields. In other words, researchers attached to these institutions may be more inclined to protect conventions than to go against the grain. In contrast, we can imagine that scholars at smaller schools, colleges, or crossdisciplinary research centers might be more inclined to engage with other disciplines. Focusing on the former institutions rather than the later, our survey finds hard test cases for our questions about the use of literary references in social sciences. Finally, by calling attention to the different forms of influence literature may (or may not) assume, the survey made it possible to dwell in more detail on how social scientists esteem literary fiction as a tool for understanding social concepts.

\section{Background}

Before conducting our survey, we first developed a typology of what we term uses of literature within the social sciences. This typology is the result of an ongoing project seeking to understand how literature might already play a role in the social sciences, no matter how small this role might appear at first glance. Our investigations were further motivated by the distinct lack of sources on the subject. While there are a number of prominent cases that call for social scientists to incorporate the insights of 


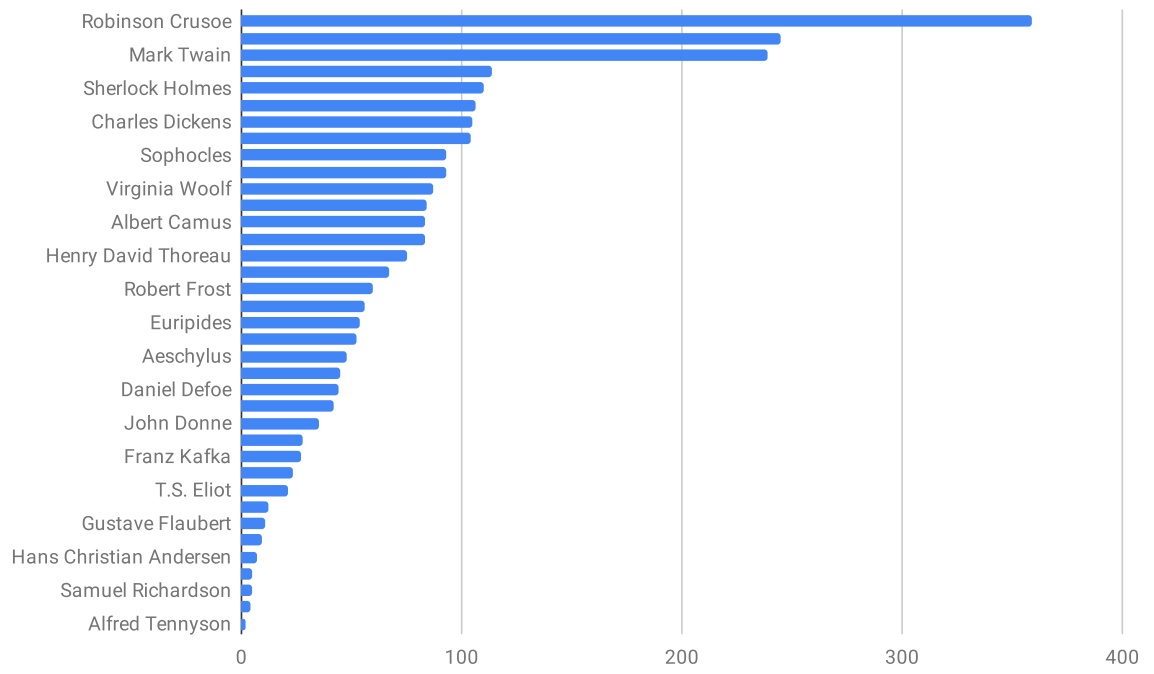

Fig. 1 Total number of social science articles referencing indicated authors and fictional characters. Chart displays search terms (author name or fictional character name) and their corresponding total number of appearances across all social science articles on JSTOR. Figure shows 19 most popular results from the compiled search term list.

literature into their research (e.g., Shiller, 2019) and teaching (e.g., Morson and Schapiro, 2017), there are hardly any that demonstrate how (and where) they might already be doing so. For those of us who wish to expound on the value of not only literature per se but the study of literature specifically, a thorough account of how experts in an adjacent field like social science might already incorporate literary objects in their scholarship is a critical starting point. The absence of a generalized account of the field therefore required us to generate our own.

To do so, we first devised a plan to comb through the entire catalog of published social science articles on JSTOR, which spans nearly a century's worth of material. Our goal at this point was to identify and categorize where and how social scientists refer to literary fiction in their published work. As will become clear, this approach's limitations-namely, its reliance on a pre-determined list of searchable terms-set the groundwork for our survey, which was designed to account for surprising or unexpected responses. Nevertheless, the survey provided valuable insight into the more fleeting references to literary fiction in published social science research.

A brief account of this JSTOR project is useful for contextualizing the results of our social science survey. First, it was necessary to generate a delimited archive of social science articles that use, in some shape or another, literary sources. For the sake of producing an adequate number of sources, we composed a list of search terms that consisted of 30 prominent Anglophone authors, along with two famous literary characters, Robinson Crusoe, and Sherlock Holmes (Fig. 1). To determine these search terms, we cross-referenced popular online media articles (including blogs, short essays, and user forums) that offered broad rankings of, for example, the most important authors of all time. To best address the historical breadth of the JSTOR catalog, the names were edited down further to focus on authors who published before the middle of the twentieth century. It goes without saying that this initial list was far from exhaustive. Instead, it was intended to produce a large enough body of results in order for us to further generate a working typology of literary references as they appeared in the articles. ${ }^{1}$ Second, we conducted a qualitative analysis of these articles alongside the rough typology of uses Michael Watts, Professor of Economics at Purdue, outlines in his study of economics and literature-the only workable typology we found.
According to Watts, economists who engage with literature to any degree tend to do so according to four different categories: 1 . eloquent description of human behavior; 2 . historical evidence conveying the context of a particular time or place; 3 . Alternative accounts of rational behavior that complement or challenge economic theory; 4. Evidence of an antimarket/antibusiness orientation in esthetic works. (2002, p. 377)

When viewed alongside the JSTOR articles, however, the limitations to Watts's typology were apparent. Most immediately, the emphasis on what one might call deep or sustained engagements with literature means that his typology will not capture those more fleeting uses of literature that make up the vast majority of literary references in the social science archive. Once one recognizes these limits, it becomes clear that any categorization or typology of literature in social science must be sufficiently flexible enough to capture the many and often surprising ways that the disciplinary fields might intersect. Of course, this latter point is underscored by the fact that Watt's original typology is concerned with economics only. By expanding our search to include the social sciences in general, we allow for a wider scale for evaluating literature's usefulness as seen by, for instance, political scientists, social theorists, and behavioral economists. After reviewing the JSTOR set of articles, we expanded on Watt's initial typology to produce a more encompassing categorization of literary uses that better accommodated the range of literary references as they appeared in the archive. Ultimately, we determined that an expanded typology of uses of literature as they appear in published social science articles must include several more categories, never mind the four in Watts's initial outline:

Literature as argument. Causal Argument/Historical data: marks studies that see literature as an agent of historical change along the lines of something a historian of the period can recognize.

Alternate Explanation: notes studies that see literary writers as rival social theorists whose arguments warrant proper countering.

Philosophical Position: refers to studies that associate an author with an argument that is developed or sustained across that author's body of work.

Literature as context. Historical Context: designates studies that use information from literary texts as a way of characterizing a 
particular historical period, without claiming that the work was an agent of change in the period.

Biography: refers to studies that cite biographical details of an author or literary source as a way of situating concurrent historical events.

Literature as metonym. Cultural Standard: names studies that refer to literary texts as a cultural metonym, for example using Shakespeare as a way of referring to Renaissance England or to Western Culture as a whole.

Parable: designates studies that refer to a literary object that has lost its original literary contextualization and now stands in for something else entirely (e.g., Robinson Crusoe as a parable for homo economicus).

Literature as decoration. Literary effects/style: accounts for those literary texts that are evoked subtly via an author's style or phrasing.

Decoration: names instances when the references to a literary text appear merely decorative and play no significant role in the argument.

Nonfiction quote: denotes direction quotations attributed to authors outside their published works.

Literature as Inspiration: marks moments in which a literary text plays no direct role in the argument but inspired the scholar's thinking.

Literature as Teaching Tool: acknowledges instances where scholars use literary texts within the classroom or to help explain a concept.

As this expanded typology suggests, our initial assessment of the JSTOR articles highlights literature's wide range of applications within the social sciences (Fig. 2). Moreover, it jumpstarts a dialog on what, exactly, constitutes a use of literature within this field. After all, it seems significant that a great portion of literary references as captured in the JSTOR survey are essentially noncritical uses-pithy quotations from authors or famous literary epigrams-when viewed from the perspective of literary studies. Nonetheless, to account for these references to literature is to acknowledge something of the role literary fiction per se plays, if not in the entire field of social science research, then in the academic conventions of social science publishing.

At the same time, our attempts to expand this typology ran into several hurdles of its own. First and foremost, our ability to generate search results from the JSTOR archive was limited by the terms we used: because any search for "literature" or "fiction" produces too many non-applicable and generalized results, one must enter specific search terms (e.g., William Shakespeare; Virginia Woolf) to produce relevant results. Along similar lines, our typology can only take shape in view of these limited sources; it is after all possible that an author or literary text that did not appear on our initial list has been received by social scientists in ways that confound expectations beyond even our expanded typology.

Finally, our reliance on both pre-conceived search terms and archived research articles prevents us from evaluating the newest trends in both literature as well as social science research. As our survey results below demonstrate, there is ample evidence that literature produced within the last twenty years has an outsized impact on those social scientists who acknowledge literary fiction as an influence in their work. The conventions of academic publishing in non-literary fields, however, might prevent researchers from likewise acknowledging these contemporary examples in their published material in favor of more familiar, canonical examples. In view of the affordances and limitations to our initial JSTOR study, we decided to approach the subject of literature and social science from another direction: by going directly to the source.

If publications are the end products of academic work, the product does not always reflect all details of the research process. Nobody leaves the scaffolding standing when the house is completed; likewise, the notes, readings, and other sources of inspiration that lay the foundation for an article or academic monograph often go unacknowledged. To be sure, simply searching for references to literary fiction in the published text of these sources is likely to return some results-for instance, the frequent conflation of the homo economicus model with the protagonist of Robinson Crusoe, albeit in a manner that elides any reference to Daniel Defoe, the author (Watson, 2017). As the example of Crusoe suggests, the small pool of literary sources that appear in the text of social science articles cannot adequately account for the wide range of influences literature might have at all stages of research. To better capture these invisible or unacknowledged uses of literature in the social science, we decided to simply ask social scientists themselves. The survey asked a few simple questions on their use (or not) of fictional literature in any stage of their academic work. The survey questions are included in the supplementary material as

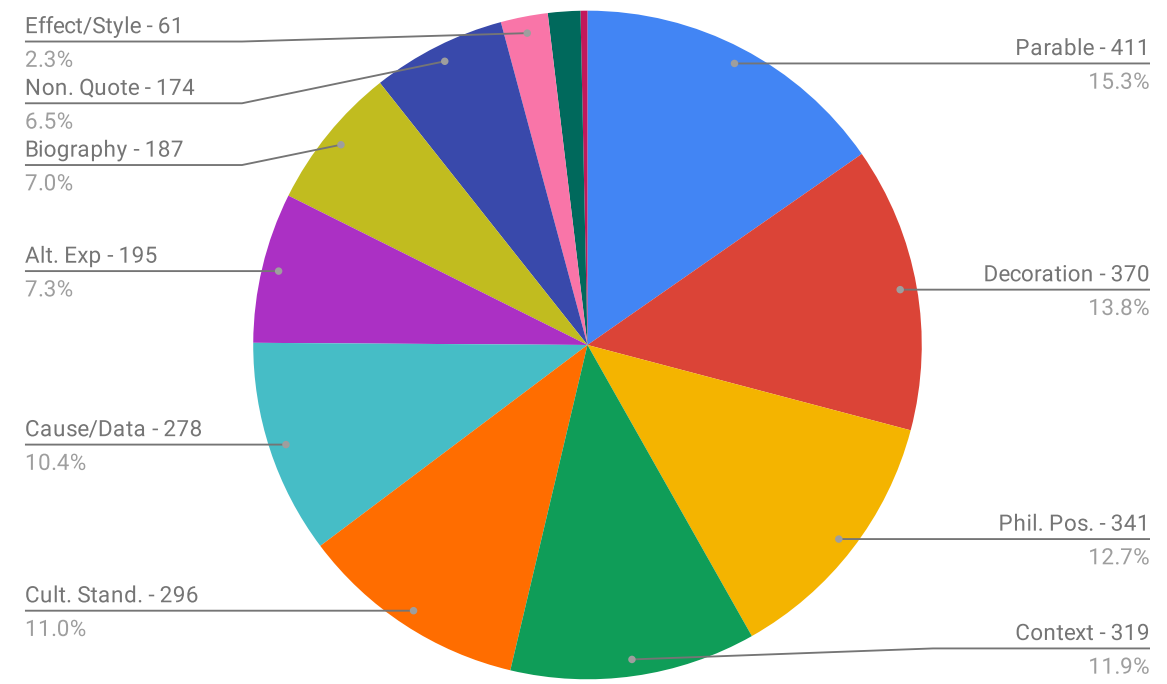

Fig. 2 Typography of literary uses in social science articles. Chart shows the proportion of literary typographies across JSTOR's social Science catalog from among our compiled search term list. The presented types originate from our expanded typography based on Watts's categorisations. 
supplementary note. We received 875 responses at a response rate of 7 percent, a number which we deemed acceptable for allowing us to detect some overall patterns. Given the use of THE rankings, the sample is dominated by North American and European social science departments. The sample includes all career stages: Ph.D students ( $35 \mathrm{pct}$.$) , postdocs and assistant professors (20 pct.), and$ tenured staff ( 42 pct.). It includes the four major social science disciplines: economics (20 pct.), sociology (31 pct.), political science (26 pct.), psychology (19 pct.), whereas a small group (4 pct.) identified with other disciplines. A full demographic breakdown (Table S.1) is included in the supplementary material.

\section{Discussion: what do social scientists say?}

To be clear, not all social scientists use literature in a manner conforming with our typology above or even consider literature a factor in their work life. In the survey, we focused on the nonexplicit uses of literature and the considerations behind their uses. In other words, the survey is meant to supplement our findings from the study of social science journals from the JSTOR digital library. The survey should not be taken as a test of the abovementioned categories developed from the empirical study of academic publications. Still, it is possible to glean some points of overlap between the two approaches. Several of these categories can be easily applied to responses from the survey, especially the categories relating to literature's inspirational value or its usefulness as a teaching tool. At the same time, other categories that feature heavily in the published articles-especially "literature as decoration" and "literature as metonym"-were hardly mentioned at all in the survey responses. The gap between what social scientists say about literature and what appears in social science articles reiterates the value of the survey, which captures some of the underlying motivations for using literature (or not) that otherwise would not come across in view of published academic work.

Even considering the general self-selection bias-i.e., respondents who react positively to the idea of using literature are also more likely to participate in the survey-93 percent agreed that "Literature often contains important insights into the nature of society and social life", while only 2 percent disagreed. However, it is one thing to acknowledge that literature offers general insights into life and quite another to affirm that literature plays a role in individual research biographies. To address this issue, we posed the question if "Reading literature played a role in the formation of your research questions or the development of your research projects."

We were somewhat surprised to learn that this was the case for almost half of the respondents (46 precent agree or totally agree), and only a third (34 percent) rejected this premise (Table 1 ). Looking at the comments in the open sections shed light on this. For some researchers there was a very clear link. For example, one respondent explained: "Toni Morrison and other women of color (Ana Castillo, for example) greatly enriched my understanding of the role of gender in society (I am a man)."

Raising the bar even higher, we then asked about publications. Publications are arguably the most delicate matter in our survey. After all, publications can make or break careers inasmuch as they factor into promotions and tenure reviews. In response to our publishing question ("How often do you quote or in other ways use a work of fiction in your publications"), 25 percent recorded occasionally using literary fiction in some form and an additional 13 percent affirmed doing so often or very often. In other words, almost 40 percent of the respondents acknowledge using literary sources in their publications (Table 2).

However, it must be stressed that these uses vary in form and substance. Based on our qualitative assessment of a subset of social science sources (outlined above), we found that explicit engagements range from the superficial (e.g., brief quotations of famous quips or observations from literary sources), the decontextualized (e.g., Robinson Crusoe functions only as a model of economic behavior), to more sustained engagements with the arguments or ideas presented in literature (e.g., Thomas Piketty's references to Jane Austen and Balzac in Capital in the TwentyFirst Century). In other words, a great many of these applications of literature do not resemble the type of work one finds in literature departments. Moreover, the depth or method for engagement is rather unsystematic.

Table 1 The role of literature in the development of research questions and projects by discipline.

\begin{tabular}{lllllll} 
Discipline & Totally disagree & Disagree & Neither agree, nor disagree & Agree & Totally agree & Total \\
\hline Economics & $15 \%$ & $27 \%$ & $24 \%$ & $23 \%$ & $11 \%$ & $100 \%$ \\
Sociology & $9 \%$ & $23 \%$ & $17 \%$ & $31 \%$ & $20 \%$ & $21 \%$ \\
Political science & $11 \%$ & $25 \%$ & $17 \%$ & $26 \%$ & $12 \%$ & $100 \%$ \\
Psychology & $11 \%$ & $18 \%$ & $27 \%$ & $32 \%$ & $34 \%$ & $100 \%$ \\
Other & $5 \%$ & $17 \%$ & $15 \%$ & $29 \%$ & $18 \%$ \\
Total & $11 \%$ & $23 \%$ & $20 \%$ & $28 \%$ & $100 \%$ \\
\hline
\end{tabular}

Note: Answers to Question 3 ("Reading literature played a role in the formation of your research questions or the development of your research projects") by academic discipline in percent. Answer scale ranges from 1 ("Totally disagree") to 5 ("Totally agree").

Table 2 Frequency of references to fiction in publications by discipline.

\begin{tabular}{|c|c|c|c|c|c|c|}
\hline Discipline & Never & Rarely & Occasionally & Often & Very often & Total \\
\hline Economics & $40 \%$ & $38 \%$ & $17 \%$ & $2 \%$ & $3 \%$ & $100 \%$ \\
\hline Sociology & $23 \%$ & $31 \%$ & $27 \%$ & $14 \%$ & $4 \%$ & $100 \%$ \\
\hline Political science & $36 \%$ & $28 \%$ & $25 \%$ & $8 \%$ & $2 \%$ & $100 \%$ \\
\hline Psychology & $32 \%$ & $29 \%$ & $27 \%$ & $10 \%$ & $2 \%$ & $100 \%$ \\
\hline Other & $10 \%$ & $27 \%$ & $39 \%$ & $12 \%$ & $12 \%$ & $100 \%$ \\
\hline Total & $31 \%$ & $31 \%$ & $25 \%$ & $10 \%$ & $3 \%$ & $100 \%$ \\
\hline
\end{tabular}


Of course, publications and research only constitute part of the work academics do at the university. Our survey also asked about teaching in order to capture other literary uses that published papers are unlikely to acknowledge. As noted above, Robinson Crusoe appears in textbooks on microeconomics in the figure of the homo economicus. Elsewhere, there are several examples of sources who call for incorporating literary fiction in the teaching of the social sciences in order to benefit from the imaginative social logics embedded in, for instance, science fiction novels (e.g., Rodgers et al., 2007; Hirschman et al., 2018). As our survey demonstrates, most of the respondents use or have used literary sources as pedagogical tools: less than a third (30 percent) never do so, most do so at least sometimes, and a few (12 percent) frequently use literature in their teaching (Table 3 ).

If we had expanded the category from literature to art in a wide sense (including, for example, movies, television series, paintings, and music) we suspect the numbers would have been significantly higher.

Finally, our survey provides some insight into what characterizes social scientists who use literature in their work. We generally find only small differences between disciplines within the field of social science, with economists marginally more skeptical of literature's usefulness in the classroom than researchers in sociology, political science, and psychology (Table 3). This confirms earlier findings. A survey from 2006 showed that 57 percent of economist disagreed with the proposition that "In general, interdisciplinary knowledge is better than knowledge obtained by a single discipline." For psychology, political science, and sociology the numbers were 9,25 and 28 percent respectively (Fourcade et al., 2015).

Larger contrasts appear when considering the career stage of the researchers. We find a very clear general pattern of earlycareer, non-tenured researchers expressing more skepticism regarding literature's insights compared to tenured and more senior researchers (Table 4). This pattern is most apparent when the respondents consider the use of literature in their own publications. A striking 75 percent of $\mathrm{PhD}$ students and 78 percent of postdocs have never quoted literature in their publications, compared to 48 percent in the senior professor group.

Arguably, this gap might simply reflect the much larger publication portfolio expected of senior professors in relation to early-career scholars, but the same pattern holds when we asked more general questions on the importance of literature.

This last point casts into relief some of the internal and generational gaps existing between senior researchers and junior and early-career researchers facing an increasingly precarious academic workplace. For early-career researchers, there is little immediate benefit to working outside established borders when recognition and professional assessment (such as promotions and tenure) still largely derive from work within disciplinary camps (Lyall, 2019, p. 2). At the same time, stepping into uncharted territory requires one to navigate disciplinary traditions, departmental gatekeeping, and new methodologies. These professional limitations are what observers have in mind when they call interdisciplinary research risky at best (e.g., Callard and Fitzgerald, 2015) and "career suicide" at worst (Bothwell, 2016).

Rather than ascribing literary interests to some form of academic maturity, then, we suspect this gap between early and laterstage researchers partly reflects how disciplines work. In general terms, it is easy to imagine how the institutional pressures on early-career researchers can translate to a stricter adherence to disciplinary guidelines. Facing an unstable job market and competing for a limited pool of external funding, these scholars are highly dependent on the recognition of their peers and will tend to be more risk-adverse with respect to publications. As noted above, explicit signals of inter- or cross-disciplinary interests may sound appealing in the abstract (and may be promoted by international funding agencies) but they face much more skepticism within academic departments and hiring committees. As a result, using literature in academic publications-and perhaps explicitly cross-disciplinary research in general-is a luxury that only the more professionally-secure researchers can afford.

This explanation might account for the lack of explicit references to literary fiction in social science research, but not the absence of more indirect literature-research relationships. For example, 39 percent of $\mathrm{PhD}$ students "totally agree" that one can "learn a lot about what humans are like from literature" as opposed to 60 percent of associate professors and over half of professors. While outside the bounds of our current project, this generational gap may also be evidence of the diminishing presence of literature departments on university campuses after successive years of administrative funding cuts and public pres-

Table 3 Frequency of using fiction in teaching by discipline.

\begin{tabular}{|c|c|c|c|c|c|c|}
\hline Discipline & Never & Rarely & Occasionally & Often & Very often & Total \\
\hline Economics & $36 \%$ & $39 \%$ & $17 \%$ & $4 \%$ & $3 \%$ & $100 \%$ \\
\hline Sociology & $27 \%$ & $30 \%$ & $25 \%$ & $12 \%$ & $6 \%$ & $100 \%$ \\
\hline Political science & $31 \%$ & $30 \%$ & $28 \%$ & $8 \%$ & $3 \%$ & $100 \%$ \\
\hline Psychology & $23 \%$ & $38 \%$ & $30 \%$ & $8 \%$ & $1 \%$ & $100 \%$ \\
\hline Other & $12 \%$ & $29 \%$ & $41 \%$ & $7 \%$ & $10 \%$ & $100 \%$ \\
\hline Total & $28 \%$ & $33 \%$ & $26 \%$ & $8 \%$ & $4 \%$ & $100 \%$ \\
\hline
\end{tabular}

Table 4 Frequency of references to fiction in publications by career stage.

\begin{tabular}{|c|c|c|c|c|c|c|}
\hline Career stage & Never & Rarely & Occasionally & Often & Very often & Total \\
\hline $\mathrm{PhD}$ & $42 \%$ & $33 \%$ & $18 \%$ & $6 \%$ & $1 \%$ & $100 \%$ \\
\hline Post doc & $40 \%$ & $39 \%$ & $14 \%$ & $4 \%$ & $3 \%$ & $100 \%$ \\
\hline Assistant professor & $28 \%$ & $35 \%$ & $25 \%$ & $9 \%$ & $2 \%$ & $100 \%$ \\
\hline Associate professor & $30 \%$ & $29 \%$ & $22 \%$ & $18 \%$ & $2 \%$ & $100 \%$ \\
\hline Professor & $20 \%$ & $29 \%$ & $34 \%$ & $12 \%$ & $5 \%$ & $100 \%$ \\
\hline
\end{tabular}




\section{Table 5 Top 20 most referenced authors.}

$\begin{array}{ll}\text { 1. George Orwell } & \text { 11. Toni Morrison } \\ \text { 2. Leo Tolstoy } & \text { 12. Franz Kafka } \\ \text { 3. Charles Dickens } & \text { 13. Harper Lee } \\ \text { 4. Fyodor Dostoevsky } & \text { 14. Chimamanda Ngozi Adichie } \\ \text { 5. William Shakespeare } & \text { 15. James Baldwin } \\ \text { 6. Jane Austen } & \text { 16. Mark Twain } \\ \text { 7. Margaret Atwood } & \text { 17. Ursula K. LeGuin } \\ \text { 8. John Steinbeck } & \text { 18. Chinua Achebe } \\ \text { 9. George Eliot } & \text { 19. Homer } \\ \text { 10. Aldous Huxley } & \text { 20. Émile Zola }\end{array}$

Note: Open-ended answers to Question 7 ("What works of fiction, if any, would you recommend to someone who wanted to understand society better?") are ranked in order of top 20 most to someone who wanted to understand socie
referenced authors by survey responses.
Table 6 Top 10 most referenced works of literature.

\author{
1. 1984 (George Orwell) \\ 2. Animal Farm (George Orwell) \\ 3. Brave New World (Aldous Huxley) \\ 4. War and Peace (Leo Tolstoy) \\ 5. The Handmaid's Tale (Margaret Atwood) \\ 6. To Kill a Mockingbird (Harper Lee) \\ 7. The Grapes of Wrath (John Steinbeck) \\ 8. Anna Karenina (Leo Tolstoy) \\ 9. Middlemarch (George Eliot) \\ 10. Brothers Karamazov (Fyodor Dostoevsky)
}

Note: Open-ended answers to Question 7 ("What works of fiction, if any, would you recommend to someone who wanted to understand society better?") are ranked in order of top 10 most to someone who wanted to under
referenced works of literature.

\section{Conclusion: the uses of trivia}

To briefly summarize, we set out to study the way social scientists use literature in two broad ways. First, we compiled a dataset comprising a century's worth of scholarship in the social sciences. Second, we conducted a survey of a large number of contemporary working social scientists. A qualitative review of the dataset revealed a number of different ways social scientists have used literature; these uses were categorizable into six broad categories, several of which contained discernible sub-categories. The survey reinforced parts of this analysis while diverging in intriguing ways. Almost all the surveyed social scientists agreed on the cognitive value of literature, and almost half (46\%) reported that literary works had played important roles in their own intellectual biographies. Yet some common uses of literature in the dataset received virtually no mention in the self-reports and the survey revealed suggestive evidence of the impact of institutional structures on whether and how scholars use literature. Ultimately the analysis points towards the value of further research. Both the list of uses compiled from the dataset and the list of works compiled from the survey are necessarily limited in scope and would benefit from a more comprehensive consideration of social scientists and their research.

But by way of conclusion, it is worth responding to the worry that much of the data collected here is somewhat less than consequential-the collection of an offhand reference here, a novel read in grad school there-and to that extent cannot answer our opening question about the nature of interdisciplinarity. Or, perhaps more soberly, it does answer the question, but simply in the negative. There is in fact not much of a meaningful use for literature in the conduct of the social sciences, and one of the pieces of evidence for the argument is the limited use such scholars have made of it thus far. Such an objection is wrong in two ways, one rather boring and one relatively more interesting. The boring objection is simply the observation that the history of a discipline does not predict its future: it would not be at all surprising to see a discipline change as a new archive of material or a new method of analysis became available to it. Indeed, this is often precisely what leads disciplines forward. The more interesting objection is the implicit premise that interdisciplinary scholarship must make its interdisciplinarity overt and extensive, and that a new interdisciplinary connection must be innovative.

We reject both halves of this second premise. The kind of interdisciplinarity we have traced here is light and casual, using a quotation here or there, and there is little that is new about it: it has been with the social sciences for much of their history. However, interdisciplinarity need not be utterly novel to be worth explicating, theorizing, and defending. Against the model of interdisciplinary development that considers the key question to be the difficulty and complexity of bringing two disciplines together, we want to highlight 
how easy it really is. If it were to become ordinary practice to read a novel and a piece of literary criticism that addressed whatever issue a given social scientist happened to be working on, this would for many social scientists simply normalize and bring to awareness the way they already work. Moreover, rather than shaming social scientists for not using literature more, we submit a better way to evoke greater respect for and greater use of literature and criticism is to highlight the ways in which they already do. Carrots, as they say, rather than sticks.

\section{Data availability}

The data that support the findings of this study are available from the corresponding author upon reasonable request.

Received: 20 July 2021; Accepted: 12 October 2021;

Published online: 03 November 2021

\section{Note}

1 The JSTOR search terms did not include John Steinbeck, who is heavily cited by the respondents in our later survey. The omission, while regrettable, underscores the usefulness of the survey's open-ended questions. Further research might well consider additional authors beyond this improvised list.

\section{References}

Arnold M (1873) Literature and dogma. Smith, Elder, and Co., London

Bothwell E (2016) Multidisciplinary research 'career suicide' for junior academics. Times Higher Education, May 3

Callard F, Fitzgerald D (2015) Rethinking interdisciplinarity across the social sciences and neurosciences. Palgrave Macmillan, London

Fessenbecker P, Yazell B (2021) Literature, economics, and a turn to content. The Minnesota review 96:69-81

Fourcade M, Ollion E, Algan Y (2015) The superiority of economists. J Econ Perspect 29(1):89-114

Hirschman D, Schwadel P, Searle R, Deadman E, Naqvi I (2018) Why sociology needs science fiction. Contexts 17(3):12-21

Leavis FR (2011) The great tradition: George Eliot, Henry James, Joseph Conrad. Faber and Faber, New York, NY

Love $H$ (2010) Close but not deep: literary ethics and the descriptive turn. New Lit Hist 41(2):371-391

Lyall C (2019) Being an interdisciplinary academic how institutions shape university careers. Palgrave Macmillan, London

Marcus S, Love H (2016) and Stephen Best. Building a better description. Representations 135(1):1-21

Martin CJ (2019) Imagine all the people: literature, society, and cross-national variation in education systems. World Polit 70(3):398-442

Meranze M (2015) Humanities out of joint. Am Hist Rev 120(4):1311-1326

Morson GS, Schapiro M (2017) Cents and sensibility: what economics can learn from the humanities. Princeton University Press, Princeton

Rodgers YV, Hawthorne S, Wheeler RC (2007) Teaching economics through children's literature in the primary grades. Read Teach 61:46-55. https:// doi.org/10.1598/RT.61.1.5

Shiller RJ (2019) Narrative economics: how stories go viral and drive major economic events. Princeton University Press, Princeton

Snow CP (1961) The two cultures and the scientific revolution. Cambridge University Press, Cambridge, UK

Watson M (2017) Rousseau's Crusoe myth: the unlikely provenance of the neoclassical homo economicus. J Cult Econ 10(1):81-96
Watts M (2002) How economists use literature and drama. J Econ Educ 33(4):377-86

World University Rankings 2019 by subject: social sciences. (2019) Times Higher Education https://www.timeshighereducation.com/world-university-rankings/ 2019/subject-ranking/social-sciences\#!/page/0/length/25/sort_by/rank/sort_ order/asc/cols/stats

\section{Acknowledgements}

The authors wish to thank Rita Felski, Anne-Marie Mai, and Pieter Vanhuysse for their helpful feedback during the design of the survey. Thanks are also due to JSTOR for making available their digital archive and to the nearly 1000 colleagues who responded to the survey and, in some cases, provided additional comments by email. Research in this article received funding by the Danish National Research Foundation (DNRF127) and the Danish Institute for Advanced Study (internal funds).

\section{Competing interests}

The authors declare no competing interests.

\section{Ethical approval}

The project design was approved by SDU-RIO (ref: 10.646). As the project does not involve human biological material, approval by the Research Ethics Committee SDU is not applicable.

\section{Informed consent}

Data collection for this study and the use of data for research were approved by SDURIO (ref: 10.646) following Danish Data Protection Law [databeskyttelsesforordningen] $\$ 10$.

\section{Additional information}

Supplementary information The online version contains supplementary material available at https://doi.org/10.1057/s41599-021-00939-y.

Correspondence and requests for materials should be addressed to Bryan Yazell.

Reprints and permission information is available at http://www.nature.com/reprints

Publisher's note Springer Nature remains neutral with regard to jurisdictional claims in published maps and institutional affiliations.

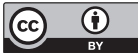

Open Access This article is licensed under a Creative Commons Attribution 4.0 International License, which permits use, sharing, adaptation, distribution and reproduction in any medium or format, as long as you give appropriate credit to the original author(s) and the source, provide a link to the Creative Commons license, and indicate if changes were made. The images or other third party material in this article are included in the article's Creative Commons license, unless indicated otherwise in a credit line to the material. If material is not included in the article's Creative Commons license and your intended use is not permitted by statutory regulation or exceeds the permitted use, you will need to obtain permission directly from the copyright holder. To view a copy of this license, visit http://creativecommons.org/ licenses/by/4.0/

(c) The Author(s) 2021 